\title{
Entre glorias y agonías: fútbol e identidad nacional en la prensa
}

\author{
Por Rodrigo Araya, Loreto Bravo y Osvaldo Corrales
}

Es una noche estrellada y en la cancha del Estadio Nacional de Chile se enfrentan las selecciones de fútbol de Chile y Brasil. Corre el minuto 85 y las sesenta mil personas que repletan el estadio vibran eufóricas frente a un resultado que, hasta pocas horas antes, se veía como imposible: la Selección de Chile vence por 3 a 0 a su similar de Brasil, en un resultado que será calificado posteriormente como "histórico". De pronto, uno a uno, los hinchas transidos por un orgullo repentino, comienzan a entonar el himno nacional. Primero es sólo un murmullo inaudible, paulatinamente se transforma en un verdadero clamor que inunda la patria con los sones de la chilenidad.

Sucesos como el descrito resultan llamativos si se considera el proceso de degradación experimentada por los símbolos que representan la identidad nacional. Cada vez menos recurridos, no suelen actualizarse masivamente ni siquiera en efemérides paradigmáticas, como, por ejemplo, la del nacimiento de la república.

El trabajo cuya síntesis se expone a continuación, se inscribe precisamente dentro del debate acerca de las transformaciones experimentadas durante las últimas décadas en el concepto de identidad nacional y los desplazamientos que se observan respecto de los lugares en que dicha identidad se actualiza. Considerando que los medios de comunicación son quizás los más importantes generadores de material simbólico en las sociedades contemporáneas, lo que este estudio se propuso fue determinar si, dentro de la prensa deportiva, existen apelaciones de tipo nacionalistas relacionadas con el fútbol y, de ser así, qué formas específicas adoptan.

\section{El tema de las identidades}

El concepto de identidad alude básicamente a la pregunta por el "yo" y se encuentra definido siempre en relación con un "otro" respecto del cual se establece una diferenciación. En este sentido se encuentra ubicado en una dimensión propiamente psicosocial y puede expresarse tanto a nivel individual como colectivo (grupal, familiar, etc.). La identidad nacional corresponde a un tipo de identidad colectiva que expresa el imaginario que permite a los particulares sentirse parte de una comunidad política: el Estado nación. En nuestro caso, corresponde a todo aquello que conduce al "sentirse chilenos" y que define un nosotros como tales.

El concepto de identidad nacional surge históricamente a partir de la necesidad de las nacientes repúblicas de hacer sentir a los ciudadanos emancipados miembros de una misma comunidad. Claramente y desde su propia definición, la identidad nacional cumple una función, cultural, política e ideológica: su rol es transformar la idea política de la nación en vivencia, sentimiento y cotidianeidad.

Como imaginario, la identidad nacional se constituye principalmente en torno a ciertos mitos fundacionales que se expresan en el conjunto de textos, líricos y épicos, que hablan de los padres de la patria, héroes que forjaron la nación y su carácter (y con él, el de sus conciudadanos). Estos textos son reproducidos en los libros y enseñados sistemáticamente en la escuela, institución responsable por excelencia de desarrollar políticas de Estado de asimilación cultural que tienen como objetivo principal el de transformar a los sujetos nacidos dentro de nuestras fronteras, en chilenos.

\section{Posmodernidad y crisis de la identidad nacional}

Los complejos procesos de cambio cultural que han acompañado a la globalización y a la posmodernidad (expresión del nuevo orden social que emerge junto con el capitalismo tardío) han hecho entrar en crisis a las identidades nacionales, fracturándolas y haciéndolas perder su capacidad aglutinante y ordenadora. 
Dentro de este nuevo orden sociocultural, las identidades nacionales no proporcionarían el espesor suficiente para enfrentar la "salida hacia fuera" que demanda el proceso globalizador (Bengoa, 1996). Esto tensa el esfuerzo hecho por los estados nacionales en América Latina desde el momento mismo de su fundación, es decir, desde los procesos de Independencia. Como sostiene Ortiz, (1999), "la noción de Estado-nación ha perdido su capacidad de definición del sentido de la vida social: por un lado, el proceso de globalización 'libera' las identidades locales del peso de la cultura nacional (por ejemplo, las culturas populares que nunca fueron plenamente integradas a la formación nacional poseen ahora un espacio nuevo, aunque conflictivo, para manifestarse); por otro lado, surge en el horizonte cultural mundializado, la posibilidad de estructurar identidades transnacionales: es el caso del consumo" (p. 117).

García Canclini también relaciona esta suerte de crisis de las identidades nacionales con la globalización. En su perspectiva, las identidades modernas han ido perdiendo sentido puesto que éstas "eran territoriales y casi siempre monolingüísticas. En cambio, las identidades posmodernas son transterritoriales y multilingüísticas" (1995, p. 30). Los símbolos tradicionales de la fundación del Estado nación, que han dado vida a políticas culturales preocupadas únicamente del patrimonio histórico, no permiten desarrollar estrategias respecto de los escenarios informacionales y comunicacionales donde también se configuran y renuevan las identidades (García Canclini, 1995).

De hecho, estos nuevos escenarios han hecho entrar en crisis el concepto mismo de "lo propio y lo ajeno" que se encuentra a la base de cualquier identidad de este tipo: las nuevas identidades operan mediante la producción industrial de cultura, su comunicación tecnológica y el consumo diferido y segmentado de bienes, en vez de apoyarse en comunicaciones orales y escritas que otrora cubrían espacios personalizados y se efectuaban a partir de interacciones próximas.

Para algunos autores, los procesos descritos anteriormente (en conjunto) no sólo comprometerían la definición de la identidad nacional, sino que harían entrar en crisis al concepto mismo de Estado-nación. Esto porque aquellas identidades que aportan una cierta cohesión y adhesión interna, se verían puestas en jaque en virtud de tales cambios, transformaciones potenciadas por el creciente deterioro de las propias instituciones fundadoras del Estado. El Estado-nación pierde aceleradamente su capacidad de proveer identidad.

\section{Los desplazamientos: el fútbol como un nuevo escenario de la identidad nacional}

En la visión de autores como García Canclini (1995) y Sarlo (Alabarces, 1998) la pérdida de sentido de buena parte de las proposiciones identitarias y el deterioro de las instituciones que las encarnaban han provocado un cierto vacío, permitiendo que emerjan otras formas de nacionalidad que, si bien existieron antes, nunca como ahora habían llenado tantos espacios. Entre estas formas, el fútbol ocupa un lugar privilegiado.

En el estallido de identidades que se producen con la posmodernidad el fútbol opera casi como único aglutinante; sus virtudes: es fácil, es universal y es televisivo, lo cual lo convierte en una verdadera máquina cultural. Por otra parte, posee un gran potencial metafórico: su desarrollo escenifica el enfrentamiento con "otro" proponiendo una forma afirmativa y primaria del "yo". Al decir de Sarlo (1998) "no es la nación, sino su sobrevivencia pulsátil".

En esta operación mimética 'selección de fútbol/nación', el periodismo desempeña un papel clave como partícipe productivo de la industria cultural. En especial, por el aporte que realiza a la construcción de la realidad social (Rodrigo, 1993). De acuerdo a esta tesis, la cobertura periodística posee una doble significación. Por una parte, sitúa al fútbol y en especial, a los avatares de la selección nacional, como tema de preocupación pública. Y por otra, para poder cumplir con lo anterior, pero también como su consecuencia, el periodismo selecciona referentes simbólicos hegemónicos (aquellos que aprendimos en la escuela y en los 
libros para niños), generando procesos identificatorios de quienes, en una misma nación, consumen esos mensajes (Martín Barbero, 1987).

En el caso chileno, donde la falta de espesor cultural ha sido destacada por recientes estudios (Subercaseaux, 1999), la interacción de la selección de fútbol con sus similares de otras naciones, brinda, periódicamente, la oportunidad para materializar algunos vagos referentes que permitirían configurar un 'nosotros' en crisis. En especial, cuando la competencia nos enfrenta con naciones con las cuales la historia compartida es rica, no sólo en cooperación, sino también en desencuentros. Es pertinente entonces preguntarse si el periodismo deportivo contribuye a instalar imaginarios identitarios y, de ser así, qué forma adquieren.

\section{El estudio}

El estudio consistió en la realización de un análisis de discurso de las páginas de la o las secciones deportivas de tres diarios de circulación nacional La Tercera, La Nación y Las Últimas Noticias publicadas en torno a tres partidos que jugó la selección chilena de fútbol contra sus similares de Argentina, Perú y Uruguay. La elección de estos partidos obedeció a la consideración de las diferencias que gravitan en el sentido común respecto a cada país: cada juego escenifica un intercambio con "otros" que portan y movilizan distintos imaginarios, en el contexto de una competencia internacional. Desde el punto de vista de la temporalidad, la lectura abarcó los números aparecidos tres días antes y tres días después de efectuado cada partido.

\section{Algunos resultados: prensa e identidad nacional}

Frente a la pregunta originaria del estudio, respecto de si se configura en el discurso de la prensa un tipo de imaginario que apela a la identidad nacional, los datos arrojados por el análisis confirman que sí. El discurso de la prensa instala un imaginario de tipo nacionalista que posee ciertas características específicas y se articula en torno a varios ejes. Antes de describir dichas articulaciones, es necesario referirse a dos hechos que parecen relevantes para apreciar adecuadamente este fenómeno.

Un primer elemento tiene que ver con que el fútbol, asociado a los avatares de la selección, representa un tema de importancia y preocupación nacional. Es propiamente lo que podríamos denominar un tema-país: no sólo ocupa titulares y portadas en función de las expectativas y los resultados obtenidos, también convoca el interés de la prensa, el pronunciamiento de las autoridades y otras expresiones públicas, además de asuntos anexos como, por ejemplo, el que los partidos jugados en el extranjero no sean transmitidos por televisión abierta. En este caso el debate pone en circulación la cuestión del derecho de la ciudadanía a presenciar en directo el desempeño de su selección.

Un segundo elemento, que se evidencia como portador de una importante carga simbólica, es el de la homonimia. En el discurso periodístico se realiza una verdadera mímesis entre la selección de fútbol y la Nación: cuando juega el cuadro representativo se habla simplemente de Chile. Por ejemplo frente al partido ante la selección argentina, el diario La Nación titulaba: "Argentina y Chile en la balanza"

En el análisis de esta forma de nominar y de los predicados que le acompañan, se confirma que el recurso no es casual ni representa en modo alguno una simple economía del lenguaje: existe un elemento de contigüidad, un movimiento metonímico, en virtud del cual en cada partido de la selección es la nación toda la que se enfrenta al "otro", a su propia historia, reafirmando o debilitando la identidad que está en juego.

Es en torno a esta operación mimética que se constituye el discurso nacionalista asociado al fútbol.

\section{La historia}


Dentro del discurso periodístico, la historia posee una doble connotación: provee un cierto fondo cultural y prefigura un cierto destino.

a) Como fondo cultural: La historia provee, en cada caso y en algunos más que en otros, de un conjunto de imaginarios en los cuales "anclar" el discurso identitario. Los mitos fundacionales aparecen reciclados y reconvertidos como justificación de dichas construcciones discursivas. Las distintas intensidades y espesores que tienen las relaciones con otros hacen que éstas apelaciones identitarias tengan más o menos fuerza. En este sentido, los casos analizados representaron tres escenarios claramente diferenciables.

Frente a Argentina el discurso periodístico articula un tipo de identidad que podríamos llamar disminuida a partir de la historia de derrotas sucesivas en los partidos que han enfrentado a ambos seleccionados:

"Si hay puntos de por medio, el marcador parece estar predestinado a señalar un empate o una victoria de los transandinos" (La Tercera)

Si el partido de Chile con Argentina es configurado por la prensa deportiva como un duelo en desiguales condiciones, el partido con Perú restituye explícita o implícitamente el drama de la guerra. La guerra del Pacífico ofrece el marco de referencia simbólico que construye el clima que rodea al partido. Las reminiscencias son elocuentes:

"Chile ya tiene listos sus pertrechos para el partido del miércoles. Aquí (no) se promete guerra." (Las Últimas Noticias.)

Con Uruguay en tanto, al no existir un fondo histórico que valide un discurso identitario, dichas apelaciones prácticamente desaparecen, manteniéndose como único elemento el de la lealtad que pude tener con la nación un entrenador foráneo:

"El destino lo puso así: el entrenador de Chile, uruguayo de nacimiento, se juega la vida en el Estadio Centenario, rodeado de un simbolismo emotivo" (Las Últimas Noticias).

El fútbol no provee "per-se" de elementos aglutinadores, sólo lo hace en función de un espesor histórico dado y casi siempre con un carácter marcadamente beligerante.

b) Como destino: Lo que podríamos denominar el "peso de la historia" se transforma en una carga que hace que para Chile sea todo más difícil, prefigurando un destino que las más de las veces resulta aciago y triste. Ante la derrota, el determinismo histórico es indiscutible. La historia se levanta como profecía:

"Fue como se esperaba. Como anticiparon todos. Como creían en Argentina y en Chile."(La Nación)

\section{Rasgos psicosociales de la chilenidad}

En el relato deportivo la selección de fútbol (ideal y simbólicamente) materializa y actualiza los rasgos prototípicos de la chilenidad, tanto los positivos (compromiso, fuerza, entrega) como los negativos (apocamiento, timidez): habitualmente la victoria transita por los primeros y la derrota por los segundos. Sin embargo, existe una característica central, un rasgo identitario esencial, que exige ser salvaguardado en cualquier escenario: la dignidad. Incluso la derrota puede ser decorosa si es que la dignidad es preservada como núcleo básico. De lo contrario, la derrota se transforma en traición (al alma nacional).

"Chile con poca convicción y menos precisión estaba muy lejos de hacer más decorosa la caída"(La Tercera). 
"A Chile lo veo sin garra, sin fuerza, sin corazón. Por último podemos ser malos, pero el corazón es lo que falta" (LN)

La demanda, o su otra faz, la carencia, no es tanto de logros como de heroicidad. Dejar la vida en el enfrentamiento salvaría de la vergüenza de no ser.

\section{Antes y después de Francia 98}

En todo caso, las expectativas de rendimiento y la definición de lo que somos (como país y deportivamente) tienen un punto de inflexión muy poderoso que marca un "antes" y un "después" y es la clasificación al Mundial de Francia 1998. Este evento rompió con el extrañamiento, el verdadero exilio que sufría Chile respecto del mundo y permitió superar la vergüenza del episodio protagonizado por el arquero Roberto Rojas en 1989 (apodado significativamente "el cóndor", imagen emblemática del escudo chileno, lo cual nuevamente nos remite a un universo simbólico lleno de significaciones identitarias).

"El renacer (...). Luego de siete años de exilio, Chile volvió a la competencia en pos de una Copa del Mundo" (La Tercera)

La clasificación a Francia constituye un mito refundacional que genera un nuevo umbral respecto del cual hacer exigencias y que en muchas ocasiones se transforma en un aumento de la frustración relativa.

\section{El drama del reconocimiento}

El punto anterior se engarza con otra expresión de carencia: lo que somos se constituye en la forma en que los otros nos ven y en cómo esto afirma o niega nuestra propia percepción. En el razonamiento periodístico, la clasificación a Francia 98 permitió superar un trauma y, a la vez, realizar importantes avances en el plano psicológico permitiendo a los chilenos ver su entorno y ser vistos de otro modo.

"Los chilenos nos hemos acostumbrado a pensar en grande. Se aprendió a confiar luego de clasificar a Francia y andar mucho mejor de lo que se esperaba, lo que fue un orgullo para todos." (La Nación)

Sin embargo, esta supuesta nueva autonomía corresponde a una aspiración que necesita constante refuerzo y reconocimiento. Tal precariedad se manifiesta en la insistencia majadera por obtener declaraciones de los oponentes de turno en las que se valoricen nuestros progresos y se reconozca a las figuras que lo representan.

"Simeone: 'Con ellos (chilenos) hay que extremar los cuidados'." (La Nación).

La paradoja es que esta autonomía es, en verdad, heterónoma.

\section{La superioridad de lo foráneo (o la dificultad de ser chileno)}

Al momento de calcular las posibilidades frente a otro equipo y de explicar (justificar) la derrota, un lugar habitualmente recurrido por la prensa se relaciona con distintos tipo de inferioridad que serían propios (constitutivos) del ser chileno, que van desde ciertos rasgos psicológicos hasta llegar a lo propiamente étnico. Este último punto, constituye un elemento revelador dentro de la elaboración de un discurso sobre la identidad nacional, por cuanto se trataría de un rasgo 'endógeno', difícilmente superable.

"Aquí también hay algo de fondo. Las contexturas físicas son diferentes y al final ese factor influye. Por ejemplo, ellos tienen como promedio un metro ochenta de estatura y están más acostumbrados que nosotros a jugar a un alto nivel." (La Nación). 
Una sub forma del drama del reconocimiento lo representa el hecho de que dentro de los discursos analizados para que un chileno sea considerado realmente como un triunfador este reconocimiento debe venir desde el extranjero. Se "es" alguien sólo si concita admiración fuera del país.

"Pero quien definitivamente se robó la película fue un joven que vestía la camiseta del Inter de Milán con el 1+8 y el nombre de Zamorano escritos artesanalmente en su espalda." (Las Últimas Noticias)

\section{Epílogo}

Construida sobre bases febles y erosionada por frustraciones y derrotas, el discurso identitario instalado por la prensa deviene, finalmente, en una no-identidad. Sin origen y sin padre, la pregunta por el ser chileno permanece flotando en el silencio.

"Congoja. No por el resultado, sino por la orfandad. ¿Qué somos? ¿Cuál es nuestra identidad? Ayer en el Centenario, nunca la Selección de Nelson Acosta pudo resolver esa pregunta. Y no hay nada más penoso que un niño perdido que no sabe su nombre" (Las Últimas Noticias)

\section{Apuntes sobre las estrategias escriturales de la prensa deportiva.}

La tercera variable considerada dentro del estudio se relaciona con la elección de los medios utilizados y las estrategias escriturales. En esta dimensión, fue posible constatar ciertas diferencias en la forma en que los distintos periódicos trataron las noticias respecto de la Selección chilena en cada uno de los casos. A este respecto, quizás lo más significativo sea el hecho de que La Tercera posee, con relación a los otros periódicos, un lenguaje futbolístico altamente tecnificado, dentro del cual se recurre frecuentemente a la reseña histórica y al lenguaje visual infográfico, mientras que La Nación y Las Últimas Noticias recurren con mucha mayor frecuencia al género de opinión, rico en alusiones al imaginario de la nacionalidad. No obstante, más que diferencias en los medios pueden observarse un conjunto de constantes en sus estrategias escriturales, más allá de las particularidades de estilo y género propias de los esfuerzos de diferenciación desplegados por los distintos periódicos. A continuación desarrollaremos algunos de ellos en la certeza de que merecen una mayor profundización.

En primer lugar, resulta particularmente visible el carácter elusivo respecto al carácter de "industria-espectáculo" que tiene el fútbol. Esto se nota, por ejemplo, en la poca cobertura dada a las gratificaciones económicas de los jugadores, a los ingresos generados por este concepto y, en general, a los montos comprometidos en el proceso eliminatorio. Si bien existen algunas alusiones marginales a estos temas, éstas no logran opacar los rasgos épicos que se le busca a dar al fútbol, donde cada juego es el episodio de una realidad universal que se autosustenta en sus códigos particulares .

Un segundo rasgo es la atribución masiva. La pretensión universalista presente en el discurso del fútbol es más una simulación identitaria que una identidad socialmente compartida. El pueblo, la hinchada, el sentimiento nacional es aludido, citado, dicho por unas voces que mediatizan la relación entre el fútbol y la gente. El pueblo no habla o habla muy poco. Los operadores de este discurso son las autoridades del fútbol (toda la gama de profesionales, dirigentes y comentaristas) y del Estado gobierno, atribuyéndose una capacidad omnisciente para pronunciarse sobre el alma nacional. El nosotros de esta identidad tiene, en la práctica, un carácter elítico, pero siempre con pretensión masiva.

Otra constante en esta construcción-simulación identitaria, es su carácter pendular y paradójico. Podríamos decir que esta identidad transita casi rítmicamente de la euforia a la depresión; de las expectativas desmesuradas, a la autoinmolación: ("Chile se para de otra manera" / "Estamos en un pozo"). Cuando la historia está en nuestra contra, es "incontrarrestable"; y cuando nos favorece, podemos ser víctimas de la mala suerte. En fin, como toda simulación espectacular, la narración obedece a la lógica del momento y de la circunstancia. 
En cuarto lugar, llama la atención que la clave escritural utilizada por el periodismo deportivo para referirse a los eventos relacionados con la Selección chilena de fútbol, es básicamente de tipo expresiva, renunciando a cualquier pretensión de objetividad. Utiliza una retórica particular, dramática, metafórica y estereotipada. La prensa deportiva se constituye en la escritura en un actor interviniente: describe pero también discute la estrategia; asume un lugar activo en la familia del fútbol.

Por último, pareciera que el discurso periodístico también está determinado por el sistema sexo-género. No se trata de que el campo esté cubierto casi exclusivamente por hombres, sino que en su discurso identitario convergen contenidos culturalmente atribuidos a lo masculino, como la valentía, la fuerza y el coraje.

ALABARCES, Pablo (1998), Lo que el estado no da, el fútbol no lo presta: los discursos nacionalistas deportivos en contextos de exclusión social, ponencia presentada en el Congreso 1998 de la Latin American Studies Association (LASA),

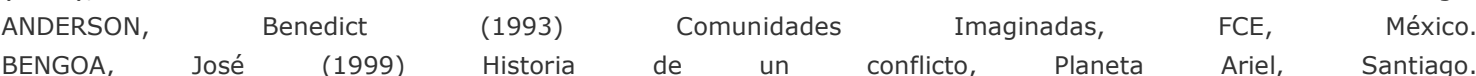
La La comunidad perdida, Ediciones Sur, Santiago. GARCÍA CANCLINI, Néstor (1995), Consumidores y Ciudadanos, Grijalbo, México. GARCÍA, M. , IBAÑEZ, J. , \& ALVIRA, F. (1986). El análisis de la realidad social. Métodos y técnicas de investigación. Madrid: Alianza. IBAÑEZ, J. (1991). El regreso del sujeto. La investigación social de segundo orden. Santiago: Amerinda. LÓPEZ-ARANGUREN, E. (1986). El análisis de contenido. En: El análisis de la realidad social. Métodos y técnicas de investigación. Madrid:

Alianza. MARTÍN BARBERO, Jesús (2000) Jóvenes: comunicación e identidad, en Boletín del Programa Iberoamérica: Unidad cultural en la Diversidad, Organización de estados iberoamericanos para la educación, la ciencia y la cultura, julio 2000 (En:

http://www.oei.es/cultura5.htm\#debate) - los medios a las Mediaciones, Ediciones Gili, Barcelona. ORTIZ, Renato (1999), Otro Territorio, Convenio Andrés Bello, Bogotá. RODRIGO ALSINA, Miquel (1993) La construcción de la noticia, Paidós Comunicación, Barcelona. SCRUTON, Roger (1994), La primera personal del plural, en Revista Estudios Públicos No 56, Santiago, Primavera 1994. SUBERCASEAUX, Bernardo (1999), Caminos interferidos: de lo político a lo cultural, en Revista de Estudios Públicos No 72, Santiago, verano 1999. 